\title{
Utilização de gordura protegida durante o terço inicial da lactação de vacas leiteiras em pastagem de coast-cross ${ }^{(1)}$
}

\author{
Duarte Vilela ${ }^{(2)}$, Maurilio José Alvim ${ }^{(2)}$, Leovegildo Lopes de Matos $^{(3)}$ e João Batista Matiolli(3)
}

\begin{abstract}
Resumo - O experimento foi realizado com o objetivo de avaliar o aumento na densidade energética de um concentrado quando se usa uma fonte comercial de gordura protegida, fornecida para vacas da raça Holandesa em pastagem de coast-cross-1 (Cynodon dactylon (L.) Pers.), durante o terço inicial da lactação. Foram utilizadas 14 vacas, todas no início da lactação e recebendo 9,6 e $3 \mathrm{~kg} / \mathrm{vaca} / \mathrm{dia}$ de concentrado (23,5\% de proteína bruta e $80 \%$ de NDT), no terço inicial (até 90 dias), médio (91 a 180 dias) e final (de 181 a 273 dias), respectivamente. Esses animais foram distribuídos, usando blocos casualizados, em dois tratamentos (sete vacas cada) determinados pelo fornecimento ou não de $700 \mathrm{~g} / \mathrm{vaca} / \mathrm{dia}$ da gordura protegida. Usou-se cerca eletrificada para auxiliar no manejo da pastagem, que se baseou em pastejo rotativo, com um dia de ocupação dos piquetes e o período de descanso variando de 25 a 32 dias no verão e no inverno, respectivamente. As produções médias de leite nos três períodos avaliados aumentaram $(\mathrm{P}<0,05)$ de 18,4, 15,2 e 13,7 kg/vaca/dia para 21,3, 17,1 e 14,4 kg/vaca/dia, com o suprimento de gordura protegida nos primeiros 90 dias do experimento. A taxa de lotação média das pastagens foi de 4,6 vacas/ha, o que possibilitou produções médias diárias de leite, no decorrer do experimento, de $72,4 \mathrm{~kg} / \mathrm{ha}$ corrigido para $3,5 \%$ de gordura para o tratamento testemunha, e de $80,4 \mathrm{~kg} / \mathrm{ha} \mathrm{com}$ o uso da gordura protegida.
\end{abstract}

Termos para indexação: pastejo rotativo, suplementação alimentar, rendimento em leite, produção leiteira.

\section{Use of rumen bypass fat for early-lactating dairy cows grazing on coast-cross pasture}

\begin{abstract}
The objective of this experiment was to evaluate the effect of a commercial rumen by pass fat source in concentrate offered to dairy Holstein cows at the first part of lactation, grazing coast-cross-1 (Cynodon dactylon (L.) Pers.) pasture. Fourteen cows at the beginning of lactation were fed on 9, 6, and $3 \mathrm{~kg} /$ cow/day of concentrate ( $23.5 \% \mathrm{CP}$ and $80 \% \mathrm{TDN}$ ) during the first (up to 90 days), second (91 to 180 days) and third period (181 to 273 days), respectively. The animals were distributed in a random design with two treatments: control and test group. The test group (seven cows) was fed addionally on $700 \mathrm{~g} / \mathrm{cow} /$ day of commercial source of rumen protected fat, as an extra energy source for the first 90 days of the experimental period. The pasture was managed under rotational grazing with one day of occupation, respecting a resting period of 25 days (spring/summer) to 32 days (fall/winter), for each paddock. Average milk yield, during the three periods, increased $(\mathrm{P}<0.05)$ from 18.4, 15.2 and $13.7 \mathrm{~kg} / \mathrm{cow} /$ day to $21.3,17.1$ and $14.4 \mathrm{~kg} / \mathrm{cow} /$ day, in response to the extra energy supplied during the first 90 days period. There was no evidence $(\mathrm{P}>0.05)$ of interaction between type of supplement and period, indicating the prevalence of a residual effect of fat supplementation. The overall stocking rate of the pasture was 4.6 cows/ha, resulting in $72.4 \mathrm{~kg}$ of fat corrected milk/ha/day for the control group and $80.4 \mathrm{~kg} / \mathrm{ha} /$ day for the group fed on the rumen protected fat.
\end{abstract}

Index terms: rotational grazing, supplements, milk yield, milk production.

\footnotetext{
(1) Aceito para publicação em 13 de fevereiro de 2002.

(2) Embrapa-Centro Nacional de Pesquisa de Gado de Leite (CNPGL), Rua Eugênio do Nascimento, 610, Dom Bosco, CEP 36038-330 Juiz de Fora, MG. Bolsista do CNPq. E-mail: vilela@cnpgl.embrapa.br, alvim@cnpgl.embrapa.br

${ }^{(3)}$ Embrapa-CNPGL. E-mail: leomatos@cnpgl.embrapa.br
}

\section{Introdução}

Diversos trabalhos têm mostrado que os sistemas de produção de leite baseados em pastagens bem manejadas requerem menores dispêndios com suplementação alimentar, e possibilitam maiores re- 
tornos líquidos. Dentre as gramíneas tropicais, as do gênero Cynodon, entre as quais o coast-cross-1, apresentam características forrageiras desejáveis para sua utilização sob pastejo, como elevada produção e distribuição anual de matéria seca, boa relação folha/colmo e alto valor nutritivo (Herrera, 1983; Alvim et al., 1998). Vilela et al. (1996) avaliaram vacas puras holandesas mantidas em confinamento ou em pastagem de coast-cross- 1 recebendo $3 \mathrm{~kg}$ de concentrado/vaca/dia, obtendo produções de 20,6 e $16,6 \mathrm{~kg} / \mathrm{vaca} / \mathrm{dia}$ de leite, respectivamente, com uma taxa de lotação média de 5,8 vacas/ha para a pastagem de coast-cross-1. Concluíram que, embora a receita comercial proveniente do leite produzido no sistema a pasto tenha sido inferior à do sistema confinado, a margem bruta foi $32 \%$ superior, indicando que o pastejo em coast-cross- 1 constitui alternativa viável para a intensificação da pecuária leiteira na Região Sudeste do Brasil. Resultados bioeconômicos semelhantes foram obtidos por Fontaneli (1999), com pastagem de Tifton-85, na Flórida.

A participação do concentrado na dieta de vacas em lactação assume maior ou menor importância, de acordo com o potencial de produção de leite do animal e do estádio da lactação. Cowan (1996) afirma que o limite de produção de leite de vacas em pastagens tropicais sem recorrer ao uso de concentrados não excede a $4.500 \mathrm{~kg} / \mathrm{lactação,} \mathrm{e} \mathrm{tem} \mathrm{a} \mathrm{qualidade} \mathrm{e}$ disponibilidade do pasto como determinantes desse limite.

Alvim et al. (1999) avaliaram estratégias de fornecimento de concentrado para vacas da raça Holandesa, mantidas em pastagem de coast-cross- 1 , em que um grupo recebia quantidade fixa de $6 \mathrm{~kg} / \mathrm{vaca} /$ dia e o outro, quantidades decrescentes de concentrado, correspondentes a 9, 6 e $3 \mathrm{~kg} / \mathrm{vaca} /$ dia, durante o primeiro, segundo e terceiro terço da lactação, respectivamente. Concluíram que, embora as produções médias de leite durante a lactação tenham sido semelhantes nos dois tratamentos $(19,1 \mathrm{~kg} / \mathrm{vaca} / \mathrm{dia})$, a estratégia de fornecimento de doses decrescentes de concentrado permitiu menor flutuação da produção de leite por área. Enquanto os animais que receberam suplementação em quantidade fixa de concentrado produziram de $64,5 \mathrm{~kg} / \mathrm{ha} /$ dia de leite com $4 \%$ de gordura, no início da lactação até $102,2 \mathrm{~kg} / \mathrm{ha} /$ dia no terço final, os grupos com níveis decrescentes produzi- ram 96,9 e 93,8 kg/ha/dia, nos respectivos períodos.

Vacas leiteiras, no início da lactação, não são capazes de consumir energia suficiente para dar suporte a produções elevadas de leite, levando-as à mobilização de reservas corporais na tentativa de suprir esse déficit. A mobilização muito intensa de tecido adiposo pode ocasionar desordens metabólicas, como cetose e fígado gorduroso (National Research Council, 2001). A estratégia mais lógica de garantir maior ingestão de energia pelas vacas em início de lactação é o incremento da densidade energética da dieta, pela inclusão de concentrados. O fornecimento de quantidades muito elevadas de concentrados para vacas em início de lactação pode acarretar vários problemas, como redução no teor de gordura do leite, acidose, depressão na digestibilidade da fibra e queda do consumo de matéria seca (Soest, 1994). No caso de vacas mantidas no pasto, o problema é agravado pela dificuldade operacional de oferecer a alimentação suplementar com concentrados ricos em amido com maior freqüência ao longo do dia.

Para incrementar a ingestão de energia sem afetar negativamente a digestibilidade ruminal da fibra dietética, a suplementação com lipídeos saponificados, insolúveis no rúmen, tem sido recomendada para vacas já alcançando balanço energético positivo, o que deve ocorrer com cinco a sete semanas após o parto (Nocek, 1995). A inclusão de lipídeos insolúveis, além de aumentar a densidade calórica da dieta sem comprometimento da degradação da fibra, possibilita maior ingestão e melhor eficiência de utilização da energia, além de possibilitar a absorção e metabolismo de substrato com melhor relação entre nutrientes lipogênicos e glucogênicos (Kronfeld et al., 1980), com reflexos na eficiência reprodutiva dos rebanhos (Schneider et al., 1988; Ferguson et al., 1990).

O objetivo deste trabalho foi avaliar o aumento na densidade energética de um concentrado quando se usa uma fonte comercial de gordura protegida fornecida para vacas da raça Holandesa em pastagem de coast-cross-1, durante o terço inicial da lactação.

\section{Material e Métodos}

O experimento foi realizado na Embrapa-Centro Nacional de Pesquisa de Gado de Leite, no Campo Experimental de Coronel Pacheco, MG, $\left(21^{\circ} 33^{\prime 2} 22^{\prime \prime}\right.$ de latitude Sul e 
$43^{\circ} 6^{\prime} 15^{\prime \prime}$ de longitude Oeste). O clima é do tipo Cwa (mesotérmico), com verões chuvosos e invernos secos, com precipitação média anual de $1.500 \mathrm{~mm}$, distribuídos de forma irregular.

Foram comparados dois sistemas de alimentação suplementar para vacas em lactação, mantidas em pastagens de coast-cross-1. No primeiro (testemunha), as vacas receberam concentrado com $23,5 \%$ de proteína bruta (PB) e $80 \%$ de NDT, nas quantidades de 9,6 e $3 \mathrm{~kg} / \mathrm{vaca} / \mathrm{dia}$, durante as fases experimentais representadas pelo terço inicial (de 1 a 90 dias), médio (de 91 a 180 dias) e final (de 181 a 273 dias) de lactação, respectivamente. Esta situação foi repetida no segundo tratamento, diferindo do primeiro tratamento apenas pela adição de $700 \mathrm{~g} / \mathrm{vaca} / \mathrm{dia}$ de uma fonte comercial (Megalac R, Church \& Dwight, Ohio) de gordura protegida (sabões de cálcio, insolúvel na fase líquida do rúmen), oferecida aos animais no terço inicial da lactação.

Foram utilizadas 14 vacas da raça Holandesa, $\mathrm{PO}$ e PC, de primeira à terceira lactação, pesando em média $523 \mathrm{~kg}$ de peso vivo, com cerca de 30 dias pós-parto e que apresentavam potencial de produção superior a $6.000 \mathrm{~kg} / \mathrm{lactação.} \mathrm{As} \mathrm{vacas} \mathrm{foram} \mathrm{distribuídas} \mathrm{nos} \mathrm{dois}$ tratamentos experimentais, em blocos ao acaso, de acordo com a ordem de lactação e época de parto.

A pastagem de coast-cross-1 foi estabelecida em área de várzea, em 1992, num solo Aluvial eutrófico (Vilela et al., 1996). Anualmente aplicaram-se $350 \mathrm{~kg} / \mathrm{ha}$ de $\mathrm{N}$, $80 \mathrm{~kg} / \mathrm{ha} \mathrm{de} \mathrm{P}_{2} \mathrm{O}_{5}$ e $280 \mathrm{~kg} / \mathrm{ha} \mathrm{de} \mathrm{K}_{2} \mathrm{O}$, fracionada em aplicações mensais, feitas em cobertura. Nos meses de menor precipitação pluvial (maio a setembro), a pastagem foi irrigada por aspersão com o principal objetivo de servir de veículo para a distribuição dos nutrientes dos adubos e, conseqüentemente, permitir manter a elevada capacidade de suporte que pode ser proporcionada por essa gramínea, quando adequadamente manejada. Nos meses de junho a setembro, a pastagem foi irrigada a cada 15 dias, com uma lâmina d'água de 25 a 30 mm, aproximadamente.

A pastagem foi dividida em duas áreas semelhantes, e estas, subdivididas com cercas eletrificadas, em 33 piquetes com $305 \mathrm{~m}^{2}$ cada um. O pastejo foi rotativo, com o período de ocupação do piquete de um dia, e o de descanso, variando de 32 dias, no inverno, a 25 dias, no verão.

Foram estimadas, semanalmente, na véspera e imediatamente após o pastejo, as quantidades de forragem disponível e residual da pastagem. Os animais entravam em cada piquete no momento em que a disponibilidade de forragem estava próxima de 5.500 e $3.000 \mathrm{~kg} / \mathrm{ha}$ de matéria seca, enquanto a quantidade de forragem residual existente no momento de saída dos animais do piquete era ao redor de 3.000 e $1.500 \mathrm{~kg} / \mathrm{ha}$ de matéria seca, na época das chuvas (outubro a março) e da seca (abril a setembro), respectivamente. Os piquetes eram providos de água e sombra artificial, à base de sombrite com malha fina.

As vacas foram ordenhadas duas vezes ao dia, às $7 \mathrm{~h} e$ às $15 \mathrm{~h} 30$, ocasião em que receberam os concentrados. O concentrado fornecido aos dois grupos de vacas foi constituído de fubá de milho (48\%), farelo de soja (35\%), farelo de trigo (15\%), calcário calcítico (1\%). No primeiro terço da lactação, as vacas receberam ainda $1 \%$ de bicarbonato de sódio. A composição média desse concentrado foi de $86 \%$ de matéria seca (MS), 23,5\% de PB na MS e $80 \%$ de NDT na MS. Com a inclusão dos $700 \mathrm{~g} / \mathrm{vaca} /$ dia de gordura protegida, para os animais do tratamento em teste, o concentrado chegou a $87 \%$ de NDT.

Os dados foram analisados conforme casualização inicial em blocos, com parcelas subdivididas, com os tratamentos com e sem gordura protegida fornecida no terço inicial da lactação, e na subparcela, as três fases experimentais, 1 a 90, 91 a 180 e 181 a 273 dias. Em relação aos dados referentes à pastagem e produção por área, foram consideradas duas repetições de área. Na comparação das médias foi usado o teste $\mathrm{F}$.

\section{Resultados e Discussão}

As amostras de pasto tomadas ao longo do experimento apresentaram, em média, teores de proteína bruta na matéria seca, variando de $13,3 \%$ no período seco (abril a setembro) a 17,0\% no período das chuvas (outubro a março), com valores médios de digestibilidade in vitro da matéria seca de 58,4 e 68\%, respectivamente (Tabela 1).

Nos primeiros 90 dias de avaliação, as produções médias de leite foram de 21,3 kg/vaca/dia quando os animais receberam a fonte extra de energia (gordura protegida) e de $18,4 \mathrm{~kg} / \mathrm{vaca} /$ dia quando os animais não receberam essa fonte energética. Além disso, foi observado um efeito residual $(\mathrm{P}<0,05)$, com produções de 17,1 e 15,2 kg/vaca/dia, durante o período de 91 a 180 dias; e de 14,4 e 13,7 kg/vaca/dia durante o

Tabela 1. Teores médios de proteína bruta $(\mathrm{PB})$ e digestibilidade in vitro da matéria seca (DIVMS) de amostras do pasto de coast-cross-1, durante o período experimental.

\begin{tabular}{lcc}
\hline Época do ano & PB (\% na MS) & DIVMS (\% na MS) \\
\hline Período seco (abril a setembro) & 13,3 & 58,4 \\
$\begin{array}{l}\text { Período chuvoso (outubro a } \\
\text { março) }\end{array}$ & 17,0 & 68,0 \\
\hline
\end{tabular}


período de 181 a 273 dias, respectivamente. Não houve interação $(\mathrm{P}>0,30)$ entre tratamentos e períodos, $\mathrm{o}$ que mostra que o efeito residual foi significativo (Tabela 2 e Figura 1). Este fato contribuiu para que as produções médias diárias de leite durante os 273 dias do experimento fossem maiores $(\mathrm{P}<0,05)$ nas vacas que receberam gordura protegida (17,5 kg/vaca/dia), em comparação com as vacas-testemunhas $(15,7 \mathrm{~kg} / \mathrm{vaca} / \mathrm{dia})$.

Ferguson et al. (1990); Jerred et al. (1990); Kim et al. (1993) e National Research Council (2001) também constataram efeitos positivos da adição de gordura protegida na dieta de vacas em lactação sobre a produção de leite. Os efeitos da suplementação energética podem apresentar reflexos a longo prazo, com incrementos na produção de leite pela maior persistência da lactação, como no presente trabalho.

As respostas em produção de leite à suplementação de gordura é curvilinear, com resposta marginal decrescente à medida que se aumenta o nível de inclusão

Tabela 2. Produção de leite (kg/vaca/dia, kg/ha/dia, $\mathrm{kg} / \mathrm{ha} / 273$ dias), taxa de lotação (vacas/ha) e variação do peso vivo de vacas da raça Holandesa em pastagem de coast-cross-1, recebendo gordura protegida no terço inicial da lactação.

\begin{tabular}{|c|c|c|c|}
\hline Fase da lactação & $\begin{array}{c}\text { Gordura } \\
\text { protegida }\end{array}$ & Testemunha & $\mathrm{EPM}(\mathrm{P})^{(1)}$ \\
\hline & \multicolumn{3}{|c|}{ Produção de leite $(\mathrm{kg} / \mathrm{vaca} / \mathrm{dia})^{(2)}$} \\
\hline 1- 90 dias & $21,3(24,5)$ & $18,4(21,3)$ & $0,69(0,04)$ \\
\hline 91-180 dias & $17,1(19,8)$ & $15,2(16,8)$ & \\
\hline $181-273$ dias & $14,4(15,7)$ & $13,7(14,9)$ & \\
\hline \multirow[t]{2}{*}{$1-273$ dias } & $17,5(20,0)$ & $15,7(17,7)$ & \\
\hline & \multicolumn{3}{|c|}{ Produção de leite $(\mathrm{kg} / \mathrm{ha} / \mathrm{dia})^{(3)}$} \\
\hline 1- 90 dias & $104,3(4,9)$ & $90,2(4,9)$ & $4,70(0,19)$ \\
\hline $91-180$ dias & $56,4(3,3)$ & $50,2(3,3)$ & \\
\hline \multirow[t]{2}{*}{$181-273$ dias } & $80,6(5,6)$ & $76,7(5,6)$ & \\
\hline & \multicolumn{3}{|c|}{ Produção de leite $(\mathrm{kg} / \mathrm{ha} /$ período $)$} \\
\hline 1- 90 dias & 9.387 & 8.118 & $467,19(17,21)$ \\
\hline $91-180$ dias & 5.076 & 4.518 & \\
\hline 181-273 dias & 7.496 & 7.133 & \\
\hline \multirow[t]{2}{*}{ Total (273 dias) } & 21.959 & 19.769 & \\
\hline & \multicolumn{3}{|c|}{ Peso vivo $(\mathrm{kg} / \mathrm{vaca})$} \\
\hline Peso inicial & 523 & 522 & $27,7(0,87)$ \\
\hline Peso aos 90 dias & 551 & 533 & \\
\hline Peso final & 568 & 570 & \\
\hline
\end{tabular}

(1)EPM: erro-padrão da média, com 6 e 2 graus de liberdade para as médias por vaca e por hectare, respectivamente; $\mathrm{P}$ : probabilidade, com os valores entre parênteses, nesta coluna, correspondendo à probabilidade encontrada para cada variável. ${ }^{(2)}$ Quanto à produção de leite (kg/vaca/dia), valores entre parênteses correspondem ao leite corrigido para 3,5\% de gordura. ${ }^{(3)}$ Em relação à produção de leite $(\mathrm{kg} / \mathrm{ha} / \mathrm{dia})$, valores entre parênteses correspondem à taxa de lotação média da pastagem (vacas/ha). de gordura na dieta. A resposta máxima em produção de leite com o uso de gordura, raramente excede $3,5 \mathrm{~kg} / \mathrm{vaca} /$ dia de leite corrigido para $4 \%$ de gordura (National Research Council, 2001). Cerca de $700 \mathrm{~g}$ de gordura suplementar são necessários para garantir uma produção de 3,5 kg de leite corrigido (Jenkins, 1997).

As elevadas produções médias de leite conseguidas, associadas à taxa de lotação de 4,6 vacas/ha, resultaram em produções totais de 21.959 e $19.769 \mathrm{~kg} / \mathrm{ha}$ de leite em 273 dias de experimento, nos tratamentos com e sem gordura protegida, respectivamente (Tabela 2). Trabalhando nessa mesma área, fornecendo $6 \mathrm{~kg} / \mathrm{vaca} / \mathrm{dia}$ de concentrado com $80 \%$ de NDT, Alvim et al. (1999) conseguiram média de $24.540 \mathrm{~kg} / \mathrm{ha}$ de leite corrigido para $4 \%$ de gordura, em 270 dias de experimento. As elevadas produções médias de leite obtidas por unidade de área, 80,4 e $72,4 \mathrm{~kg} / \mathrm{ha} /$ dia de leite corrigido para 3,5\% de gordura, para os tratamentos com e sem gordura protegida, permitem estimativas de produções anuais de leite de 29.346 e $26.431 \mathrm{~kg} / \mathrm{ha} / \mathrm{ano}$. Estas estimativas

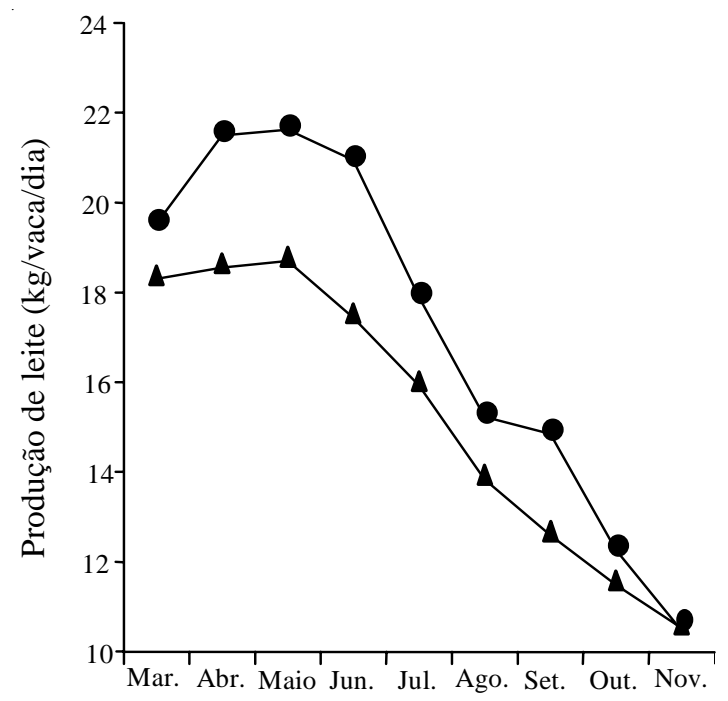

Meses

Figura 1. Produção de leite de vacas Holandesas em pastagem de coast-cross-1, durante 273 dias de lactação, em razão do não-fornecimento $(\boldsymbol{\Lambda})$ e do fornecimento $(\mathbf{O})$ de gordura protegida nos primeiros 90 dias de lactação. 
ficam aquém de $37.959 \mathrm{~kg} / \mathrm{ha} /$ ano de leite corrigido para $4 \%$ de gordura, com a utilização de nível suplementar fixo de $6 \mathrm{~kg} / \mathrm{vaca} /$ dia de concentrado, conforme experimento realizado nessa mesma pastagem por Alvim et al. (1997).

Não foram detectadas diferenças $(P>0,20)$ entre tratamentos nos teores médios de gordura, sólidos totais e proteína do leite (Tabela 3). Tendência de elevação nos teores de gordura do leite foi constatada por Kim et al. (1993), e de redução de 0,1 a 0,15 unidades porcentuais no teor de proteína do leite de vacas que receberam suplementação com lipídeos foi observada por Kim et al. (1993) e Palmquist \& Jenkins (1980). Essa redução média no teor de proteína do leite também foi detectada no presente experimento; entretanto, o protocolo experimental, e principalmente o número de animais experimentais usados, não possibilitaram estimativa mais precisa do erro experimental, que permitisse definir como efeito da suplementação lipídica as diferenças encontradas nos teores de proteína do leite $(0,1 \%)$, nos dois períodos experimentais iniciais. Essa pequena queda, mesmo se fosse significativa, não reduziria a produção total de proteína do leite, que seria até maior no grupo suplementado com gordura protegida, o que é condizente com relatos do National Research Council (2001).

Tabela 3. Teores de gordura, sólidos totais e proteína no leite produzido por vacas Holandesas em pastagem de coast-cross-1, recebendo gordura protegida no terço inicial da lactação.

\begin{tabular}{cccc}
\hline Fase da lactação & Gordura protegida & Testemunha & EPM $(\mathrm{P})^{(1)}$ \\
\hline & 4,5 & Gordura $(\%)$ & $0,12(0,63)$ \\
1-90 dias & 4,2 & 4,5 & \\
91-180 dias & 4,1 & 4,4 & $0,25(0,45)$ \\
181-273 dias & \multicolumn{4}{c}{ Sólidos totais } \\
1-90 dias & 13,0 & 13,3 & \\
91-180 dias & 12,9 & 13,2 & \\
$181-273$ dias & 12,9 & 12,9 & $0,05(0,22)$ \\
& & Proteína $(\%)$ & \\
1-90 dias & 2,9 & 3,0 & \\
91-180 dias & 3,0 & 3,1 & \\
$181-273$ dias & 3,1 & 3,1 & \\
\hline
\end{tabular}

(1)EPM: erro-padrão da média com 6 graus de liberdade; P: probabilidade, com os valores entre parênteses, nesta coluna, correspondendo à probabilidade encontrada, com relação a cada variável.
O fornecimento de concentrado com fonte de gordura protegida, aumentando a densidade energética do alimento suplementar, apesar de ter aumentado significativamente a produção de leite por vaca e a produção de leite por hectare, não se mostrou viável economicamente, já que o custo da energia extra fornecida aos animais é mais elevado que o valor a ser recebido pelo produtor em razão do leite produzido a mais por esses animais. O incremento médio de produção de leite corrigido para 3,5\% de gordura, em resposta à inclusão de $700 \mathrm{~g}$ por dia de gordura insolúvel na dieta de vacas leiteiras, nos primeiros 90 dias de experimento, foi de $2,3 \mathrm{~kg} / \mathrm{vaca} / \mathrm{dia}$. O intervalo de confiança, com $95 \%$ de probabilidade, calculado para essa diferença, é de 1,12 a $3,47 \mathrm{~kg} / \mathrm{vaca} / \mathrm{dia}$, equivalentes a um incremento total, nos 273 dias de experimento, de 4,8 a $15,0 \mathrm{~kg}$ de leite com $3,5 \%$ de gordura por quilograma da fonte comercial de gordura insolúvel fornecida no início do experimento (cada vaca consumiu um total de $63 \mathrm{~kg}$ da fonte comercial de gordura insolúvel no rúmen). Esse intervalo de confiança mostra o nível de incerteza ou o risco associado à suplementação com gordura protegida no início da lactação, em vista do preço recebido pelo leite (A, B ou C) entregue pelo produtor, fator determinante da adoção dessa estratégia suplementar.

Isso não determinaria definitivamente a inviabilidade da utilização de suplementação com lipídeos insolúveis no rúmen, uma vez que outras prováveis vantagens de tal procedimento estratégico de suplementação de pastagens tropicais para animais de elevada exigência nutricional, como seus efeitos sobre os índices de fertilidade do rebanho, não foram objeto de avaliação no presente estudo, principalmente porque o protocolo experimental não o permitiria, e também pelo número de animais experimentais utilizado. $\mathrm{O}$ fornecimento de ácidos graxos insolúveis no rúmen, com o intuito de alterar o balanço energético de vacas em lactação também altera a função ovariana, com conseqüente aumento no desenvolvimento folicular (Lucy et al., 1991). 
A inclusão de gordura na dieta de vacas em lactação aumenta o número de folículos e o tamanho dos folículos dominantes. Não está ainda devidamente esclarecido se essa dinâmica folicular exerce efeito positivo sobre o desempenho reprodutivo (National Research Council, 2001).

No presente estudo, não foi avaliada a condição corporal dos animais durante o terço inicial da lactação. A longo prazo, entretanto, o comportamento dos animais dos dois grupamentos experimentais quanto à variação no peso vivo médio não mostrou diferença em resposta à energia extra consumida no início da lactação (Figura 2). Um sumário de 20 estudos conduzidos com vacas recebendo suplementação lipídica (Staples et al., 1998) mostra pouca evidência de uma correlação entre mudança no balanço energético e taxa de concepção das vacas, apesar do aumento observado nas taxas de concepção de vacas recebendo gordura inerte no rúmen como suplemento alimentar (Schneider et al., 1988; Ferguson et al., 1990).

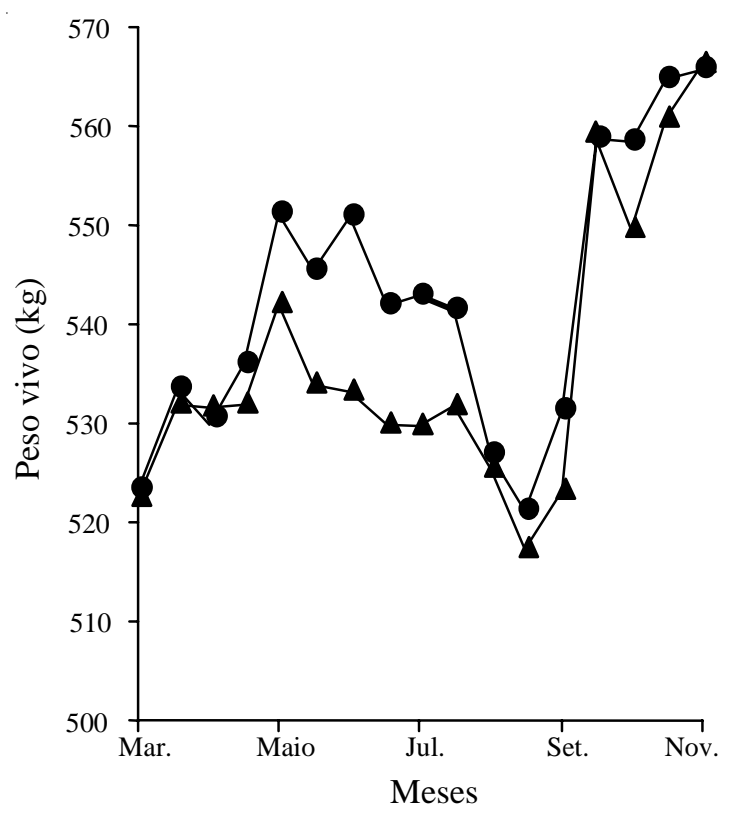

Figura 2. Mudanças no peso vivo de vacas Holandesas em pastagem de coast-cross-1, durante 273 dias de lactação, em razão do não-fornecimento $(\boldsymbol{\Lambda})$ e do fornecimento () de gordura protegida nos primeiros 90 dias de lactação.

\section{Conclusões}

1. O fornecimento de $700 \mathrm{~g} / \mathrm{vaca} / \mathrm{dia}$ de gordura protegida, na fase inicial de lactação, proporciona aumento na produção de leite ao longo de toda a lactação de vacas da raça Holandesa em pastagem de coast-cross- 1 .

2. Para se tornar economicamente viável, o preço de $1 \mathrm{~kg}$ da fonte comercial de gordura protegida deve ser inferior ao valor recebido pelo produtor na Região Sudeste do Brasil, como pagamento por $9,0 \pm 5,1 \mathrm{~kg}$ de leite com $3,5 \%$ de gordura.

\section{Referências}

ALVIM, M. J.; VERNEQUE, R. S.; VILELA, D.; CÓSER, A. C.; BOTREL, M. de A.; REZENDE, G. M. Estratégia de fornecimento de concentrado para vacas da raça Holandesa em pastagem de coast-cross. Pesquisa Agropecuária Brasileira, Brasília, v. 34, n. 9, p. 1711-1720, set. 1999.

ALVIM, M. J.; VILELA, D.; LOPES, R. S. Efeitos de dois níveis de concentrado sobre a produção de leite de vacas da raça Holandesa em pastagem de Coast-cross (Cynodon dactylon (L.) Pers.). Revista da Sociedade Brasileira de Zootecnia, Viçosa, MG, v. 26, n. 5, p. $967-$ 975, 1997.

ALVIM, M. J.; XAVIER, D. F.; BOTREL, M. A. Resposta do coast-cross (Cynodon dactylon (L.) Pers.) a diferentes doses de nitrogênio e intervalos de cortes. Revista Brasileira de Zootecnia, Viçosa, MG, v. 27, n. 5, p. 833840, 1998.

COWAN, R. T. Milk production from grazing systems in northern Australia. In: SIMPÓSIO INTERNACIONAL O FUTURO DOS SISTEMAS DE PRODUÇÃO DE LEITE NO BRASIL, 1995, Juiz de Fora. Anais... Juiz de Fora: Embrapa-CNPGL, 1996. p. 41-54.

FERGUSON, J. D.; SKLAN, D.; CHALUPA, W. V.; KRONFELD, D. S. Effects of hard fats on in vitro and in vivo rumen fermentation, milk production, and reproduction in dairy cows. Journal of Dairy Science, Champaign, v. 73, n. 10, p. 2864-2879, 1990.

FONTANELI, R. S. Forage systems per year-round grazing by lactating dairy cows. 1999. $220 \mathrm{f}$. Thesis (Ph.D.) - University of Florida, Gainesville.

HERRERA, R. S. La calidad de los pastos. In: INSTITUTO DE CIENCIA ANIMAL (Havana, Cuba). Los pastos en Cuba. Havana, 1983. t. 2, p. 59-115. 
JENKINS, T. C. Success of fat in dairy rations depends on the amount. Feedstuffs, Minneapolis, v. 69, n. 2, p. 1112, 1997.

JERRED, M. J.; CARROL, D. J.; COMBS, D. K.; GRUMMER, R. R. Effects of fat supplementation and immature alfalfa to concentrate ratio on lactation performance of dairy cattle. Journal of Dairy Science, Champaign, v. 73, n. 10 p. 2842-2854, 1990.

KIM, Y. K.; SCHINGOETHE, J.; CASPER, D. P.; LUDENS, F. C. Supplemental dietary fat from extruded soybeans and calcium soaps of fatty acids for lactating cows. Journal of Dairy Science, Champaign, v. 76, n. 1, p. 197-204, 1993.

KRONFELD, D. S.; DONOGHUE, S.; NAYLOR, J. M.; JOHNSON, K.; BRADLEY, C. A. Metabolic effects of feeding protected tallow to dairy cows. Journal of Dairy Science, Champaign, v. 63, n. 4, p. 545-552, 1980.

LUCY, M. C.; STAPLES, C. R.; MICHEL, F. M.; THATCHER, W. W. Effect of feeding calcium soaps to early postpartum dairy cows on plasma prostaglandin $\mathrm{F}_{2}$ a soaps, luteinizing hormone, and follicular growth. Journal of Dairy Science, Champaign, v. 74, n. 2, p. 483489, 1991.

NATIONAL RESEARCH COUNCIL (Washington, Estados Unidos). Nutrient requirements of dairy cattle. 7. ed. Washington: National Academy Press, 2001.381 p.
NOCEK, J. E. Nutritional considerations for the transition cow. In: CORNELL NUTRITION CONFERENCE FOR FEED MANUFACTURERS, 1995, Rochester. Proceedings... Ithaca: Cornell University, 1995. p. 121137.

PALMQUIST, D. L.; JENKINS, T. C. Fat in lactation rations: review. Journal of Dairy Science, Champaign, v. 63, n. 1, p. 1-14, 1980.

SCHNEIDER, P.; SKLAN, D.; CHALUPA, W.; KRONFELD, D. S. Feeding calcium salts of fatty acids to lactating cows. Journal of Dairy Science, Champaign, v. 71, n. 9, p. 2143-2150, 1988.

SOEST, P. J. van. Nutritional ecology of the ruminant. 2. ed. Ithaca: Cornell University Press, 1994.

STAPLES, C. R.; BURKE, J. M.; THATCHER, W. W. Influence of supplemental fats on reproductive tissues and performance of lactating cows. Journal of Dairy Science, Champaign, v. 81, p. 856-871, 1998.

VILELA, D.; ALVIM, M. J.; CAMPOS, O. F.; RESENDE, J. C. Produção de leite de vacas holandesas em confinamento ou em pastagem de coast-cross. Revista da Sociedade Brasileira de Zootecnia, Viçosa, MG, v. 25, n. 6, p. 1228-1244, 1996. 